\title{
Práticas pedagógicas e profissionalidade docente: Diálogo pautado na ludicidade e na mobilização de saberes
}

\author{
Pedagogical practices and the education of teachers: Dialogue based on playfulness and \\ mobilization of knowledge \\ Prácticas pedagógicas y profesionalidad docente: El diálogo basado en la ludicidade y la \\ movilización del conocimiento
}

Recebido: 02/07/2021 | Revisado: 06/08/2021 | Aceito: 09/08/2021 | Publicado: 12/08/2021

\author{
Indaia Schock \\ ORCID: https://orcid.org/0000-0002-9248-9514 \\ Universidade Federal de Santa Maria, Brasil \\ E-mail: idaindaia@hotmail.com \\ Janaína Schock Strappazzon \\ ORCID: https://orcid.org/0000-0003-2481-2057 \\ Universidade Federal de Santa Maria, Brasil \\ E-mail: janainaschock@gmail.com \\ Lílian dos Santos Pomina de Moura \\ ORCID: https://orcid.org/0000-0003-2242-1378 \\ Universidade Federal de Santa Maria, Brasil \\ E-mail: lilipomina@gmail.com \\ Adriana Moreira da Rocha Veiga \\ ORCID: https://orcid.org/0000-0002-5804-3375 \\ Universidade Federal de Santa Maria, Brasil \\ E-mail: adrianaufsm@gmail.com
}

\begin{abstract}
Resumo
Buscamos neste artigo voltar o nosso olhar ao exercício da profissionalidade docente e a forma como esta movimenta as práticas pedagógicas. Para tal buscamos estabelecer diálogos entre os estudiosos do tema a fim de compreender de que maneira se dá a composição dos saberes docentes, como estes são construídos e articulados no exercício diário da profíssão auxiliando no processo contínuo deste "ser sujeito artífice do seu oficio," a partir de (Freire, 1979,1987, 2004), (Alliaud, 2015), (Nóvoa, 1995), (Tardif, 2012). O nosso objetivo, portanto, é compreender qual o papel exercido pelas vivências e como estas contribuem para a construção e desconstrução do educador em um movimento que se faz através da convivência e das experiências compartilhadas dentro do universo educacional. Exploramos a ludicidade como ferramenta de ensino a ser trabalhada no desenvolvimento da aprendizagem, tanto no contexto diário entre os pares quanto no seu processo de interação com os discentes. Agregamos a essa ação, a nossa visão sobre a maneira com que diferentes ambiências influenciam na constituição da identidade do educador.
\end{abstract}

Palavras-chave: Práticas pedagógicas; Profissionalidade docente; Saberes.

\begin{abstract}
In this article, we turn our attention to the education among teachers, and the way in which it moves pedagogical practices. To this end, we seek to establish dialogues between scholars of the subject in order to understand how the composition of teaching knowledge takes place, how it is constructed and articulated in the daily practice of the profession, helping in the ongoing process of this "being a craftsman of his craft," from (Freire, 1979, 1987, 2004), (Alliaud, 2015), (Nóvoa, 1995), (Tardif, 2012). Our objective, therefore, is to understand the role played by the experiences and how they contribute to the construction and deconstruction of the educator in a movement that takes place through coexistence, and shared experiences within the educational universe. We explore playfulness as a teaching tool to be worked on in the development of learning, both in the daily context among peers and in its interaction process with students. We add to this action, our vision of the way in which different environments influence the constitution of the educator's identity.
\end{abstract}

Keywords: Pedagogical practices; Education of teachers; Knowledge.

\section{Resumen}

En este artículo buscamos dirigir nuestra mirada hacia el ejercicio de la profesionalidad docente y la forma en que mueve las prácticas pedagógicas. Para ello, buscamos establecer diálogos entre académicos sobre el tema con el fin de comprender cómo se da la composición del conocimiento docente, cómo se construye y articula en el ejercicio diario de la profesión, ayudando en el proceso continuo de este "ser". un artesano de su oficio. "de (Freire, 1979, 1987, 
2004), (Alliaud, 2015), (Nóvoa, 1995), (Tardif, 2012). Nuestro objetivo, por tanto, es comprender el papel que juegan las experiencias y cómo contribuyen a la construcción y deconstrucción del educador en un movimiento que se da a través de la convivencia y experiencias compartidas dentro del universo educativo. Exploramos la alegría como herramienta didáctica a trabajar en el desarrollo del aprendizaje, tanto en el contexto cotidiano entre pares como en su proceso de interacción con los alumnos. A esta acción le sumamos nuestra visión de la forma en que los diferentes entornos influyen en la constitución de la identidad del educador.

Palabras clave: Prácticas pedagógicas; Profesionalismo docente; Conocimiento.

\section{Introdução}

Educar se trata de afazer complexo e legítimo, pois, implica em acompanhar as questões culturais e também as evoluções tecnológicas na medida em que estas se manifestam através da sociedade e das instituições. Mais do que simplesmente mobilizar e transmitir conteúdos, os educadores e as instituições têm compromisso moral com seu patrimônio social para com aqueles que educam. Ainda assim, por mais necessária e relevante que seja a educação formal, esta carece de compreensão social sobre sua importância.

A educação sofre uma crise de identidade agravada pela incompreensão no que se refere à qualidade e legitimidade. Segundo (Alliaud, 2015, p. 320), "para ensinar hoje, professores e professoras têm que criar condições que não são dadas como garantidas, aconteça o que acontecer”. Neste convívio diário os docentes ensinam aos seus alunos conhecimentos tecnicistas ${ }^{1}$ através de disciplinas como matemática, português, geografia, para, além disso, cabe ao docente assegurar a apropriação dos conhecimentos incentivando e desenvolvendo nos discentes suas habilidades para que dessa forma eles interajam uns com os outros através de suas vivências e de suas interações com o mundo (Freire, 1987). Embora ao profissional da educação seja sempre gratificante esta construção de conhecimento, é na participação e construção de um caminho ele sente na pele as mazelas e carências estruturais, principalmente em um país como o Brasil que tem muitos problemas históricos derivados de uma injustiça social, cabendo à escola diminuir esse abismo no ponto de partida da formação para que possibilite dessa forma um sonho mínimo de justiça social.

Para velejar neste campo da educação é necessário vocação e formação para não acabar sendo mero replicador de um conhecimento pasteurizado e não refletido ou não dialogado, para tal o profissional da educação precisa saber buscar dentro de si a gama de saberes que este acumula ao longo da vida sendo que ele deriva de diversos lugares de fala, este nasceu um cidadão com direitos e obrigações e com uma compreensão de mundo e sociedade a qual ele integra, este docente já foi aluno em um período de seu caminho, ele foi aluno ao estudar a arte da docência e aprender a ser docente, e ele também foi docente ao entrar na sua primeira sala de aula e ir se experimentando no decorrer do percurso, todos estes processos formativos compõem a complexidade de ser quem se é em um exercício contínuo e diário de "saber e fazer, teoria e prática, pensamento e ação" (Alliaud, 2015, p. 322).

Refletir a educação e o papel do educador neste processo é vislumbrar um manancial de possibilidades para fazer brotar no mundo as mudanças necessárias, estas possibilidades derivam de ações e interlocuções que precisam ser refletidas para compor um saber autônomo, engajado e dinâmico. Pensar um modelo de educação que atenda às exigências sociais e esteja comprometida com a sociedade moralmente é papel de toda a sociedade, porém esta tarefa agiganta-se na mão do docente "Não se pode chegar à conscientização crítica apenas pelo esforço intelectual, mas também pelas práxis: pela autêntica união da ação e da reflexão" (Freire, 1979, p.47), muito mais do que fazer parte do mundo, é necessário formar cidadãos com consciência de mundo. A docência é a profissão dos que não se omitem, não se silenciam, ela está presente sempre que a

\footnotetext{
${ }^{1}$ A partir do pressuposto da neutralidade científica e inspirada nos princípios de racionalidade, eficiência e produtividade, a pedagogia tecnicista advoga a reordenação do processo educativo de maneira a torná-lo objetivo e operacional. [...] na pedagogia tecnicista o elemento principal passou a ser a organização racional dos meios, ocupando o educador e o educando posição secundária. A org anização do processo converteu-se na garantia da eficiência, compensando e corrigindo as deficiências do educador e maximizando os efeitos de sua intervenção. (Saviani, 2013, p.382).
} 
sociedade necessita dela.

\section{Metodologia}

Para conseguir amparar o caminho que o método percorreu cabe um breve conceito ao que entendemos como ser a metodologia. "Entendemos por metodologia o caminho do pensamento e a prática exercida na abordagem da realidade". (Minayo, 2002, p.16). Desta forma buscamos refletir a profissionalidade dos docentes para dialogar sobre quais são os saberes mobilizados em suas práticas pedagógicas; este movimento busca refletir e para isso citamos Arroyo quando este refere que a melhor forma para isso é: "Colocando seu ofício de mestre no centro da reflexão teórica e das políticas educativas" (2000, p.10). Neste sentido, por se tratar de uma pesquisa em educação e por esta ser uma ciência humana "Descartes defendeu o método dedutivo como aquele que possibilitaria a aquisição do conhecimento através da elaboração logica de hipóteses e da busca de sua confirmação ou negação". (Kauark, 2010, p.22).

Para construir as interlocuções tecemos nossas teias de pensamento em autores que se propuseram a refletir sobre o tema, uma vez que na pesquisa em educação é necessário levar em consideração uma multiplicidade de aspectos. Como elucidam Ghedin e Franco (2011, p.145), “conhecer significa tornar-se hábil em descortinar os horizontes escondidos por trás das aparências".

Buscamos neste estudo apreendermos as práticas pedagógicas, objetivando a compreensão e a complexidade exigida desta para iniciá-la neste princípio e historicidade. Ainda no que se refere ao método, a nossa compreensão é que pesquisar em educação qualitativamente seja uma postura adequada, por predominantemente tratarem-se de assuntos imensuráveis.

A pesquisa qualitativa responde a questões muito particulares. Ela se ocupa, nas Ciências Sociais, com um nível de realidade que não pode ou não deveria ser quantificado. Ou seja, ela trabalha com o universo dos significados, dos motivos, das aspirações, das crenças, dos valores e das atitudes, o que corresponde a um espaço mais profundo das relações, dos processos e dos fenômenos que não podem ser reduzidos à operacionalização de variáveis. (Minayo, 2002, p.21).

Desta forma nos utilizamos da pesquisa bibliográfica para revisitar a obra dos autores e dentro da compreensão dos textos e obras luzir os quão atuais seguem os temas e a necessidade de diálogo acerca destes para que assim a ciência da educação e a profissionalidade docente mantenha sempre sobre perspectiva, considerando todas as variáveis contidas no tempo espaço a qual estas estão alocadas. Revisitar as bibliografias é estar constantemente disposto a pensar o lugar docente e a forma como este exerce seu papel social atendendo as demandas e construindo futuros.

\section{Resultados e Discussão}

Contextualizamos aqui nossas análises e discussões sobre a profissionalidade docente e os saberes mobilizados no exercício da prática pedagógica, como os professores tratam esta construção de saberes que se dá no exercício da sua profissionalidade e de que maneira este diálogo se constrói. Ainda neste sentido buscamos uma compreensão das práticas pedagógicas através da ludicidade e de que forma estas práticas auxiliam nas vivências dos docentes e na interação com seus alunos. Em um último movimento, trazemos as ambiências em que o docente se constrói, apoiando-nos em (Freire, 1979,1987, 2004), (Alliaud, 2015), (Nóvoa, 1995) e (Tardif, 2012). 


\subsection{Profissionalidade Docente e os Saberes Mobilizados}

A profissionalidade ${ }^{2}$ docente é mediatizada no exercício diário de sua profissão. O educador possui uma formação prévia ocorrida no ambiente acadêmico, em cujo contexto estudou conceitos, interagiu com autores e de certa forma adentrou a docência através dos estágios supervisionados obrigatórios na sua formação inicial; ainda no caminho da formação inicial mobilizou conhecimentos teóricos e suas práticas aconteceram de formas supervisionadas. Muito se originou de provocações íntimas em suas experiências educacionais, as memórias introjetadas nos bancos escolares que podem ou não estarem conscientes de forma orientada, mas que contribuíram no seu processo construtivo, desde o percurso para ir à escola, as dificuldades ou facilidades que permeiam este caminho, os aromas, estações do ano, bem como a estrutura escolar auxiliam na construção desta jornada, muitas vezes estas se introduzem de forma indelével que este educador não percebe, mas que influenciam sua busca bem como a forma com que trilhará o percurso. "Esses são sujeitos que se constituem historicamente e que estão em um movimento dialético, portanto a análise de caráter histórico- singular é o singular que revela o novo ou os fenômenos sociais”. (Braga \& Rodrigues, 2020, p. 957).

Quando este docente inicia o exercício de seu ofício ele mergulha dentro das vivências diárias da educação, dessa forma ele passa a interagir com seus educandos e começa então o exercício de efetivação deste aprendizado de fato. Segundo Freire é dentro desta dinâmica que o educador começa a ser experimentado "desta maneira, o educador já não é o que apenas educa, mas o que, enquanto educa, é educado, em diálogo com o educando que, ao ser educado, também educa.” (Freire, 1987 p.39).

Quando pensamos na formação inicial de professores compreendemos que esta é de fundamental importância, entretanto ela é apenas o ponto de partida, pois é a partir dela que o docente começa sua jornada de conhecimento. Segundo Pimenta "[...] a formação passa sempre pela mobilização de vários tipos de saberes: saberes de uma prática reflexiva, saberes de uma teoria especializada, saberes de uma militância pedagógica" (2012, p.33), o educador necessita de formação contínua, pois é na interação social que a educação acontece, para que o educador se mantenha em constante reflexão sobre sua docência ele precisa se inter-relacionar e refletir estas interações uma vez que a educação não pode ser tratada como um exercício de constante repetição, ainda que muitos conceitos sejam tecnicistas a reflexão deles acontece através do olhar humano e do significado que este atribui ao processo.

Este olhar é particular e traz consigo toda a carga que este educador sentiu na construção de seu saber, sendo ela positiva ou não, este educador segue em processos onde ele se constrói, desconstrói-se e reconstrói-se novamente em ciclos contínuos, segue sendo particular e de impossível repetição, pois o lugar de fala mesmo que semelhante é ímpar a cada sujeito e deriva da sua forma de luzir e vivenciar cada situação. "Nesse sentido, auto(trans)formação docente em meio as diferentes trajetórias profissionais, demanda assumir a complexidade como cerne da constituição dos indivíduos”. (Pires \& Veiga, 2020, p.977)

Constantemente em debate, as práticas pedagógicas são estruturadas com a finalidade de interação na dinâmica ensino aprendizagem, e para isso, o aluno precisa se sentir parte do processo, cabendo ao docente a orientação deste no caminho do conhecimento. Segundo (Tardif, 2012), muito mais do que um detentor de conhecimento o educador necessita exercer sua capacidade de agente facilitador e para isso necessita de "habitus e de habilidades, de saber-fazer e de saber ser" (p.39), muito mais do que ser a pessoa que retém e despeja o conhecimento, o educador precisa intermediar este processo de troca de conhecimento e ainda considerar que a aprendizagem se dá de maneiras diferentes para pessoas diferentes tornando essa dinâmica mais difícil. Jamais uma classe de alunos aprenderá ou terá o mesmo rendimento que outra, pois os seres humanos

\footnotetext{
${ }^{2}$ A imagem da profissionalidade ideal é configurada por um conjunto de aspectos relacionados com os valores, os currículos, as práticas metodológicas ou a avaliação (Nóvoa, 1995, p.66).
} 
são únicos em suas capacidades, assim é impossível repetir uma aula mecanicamente e obter o mesmo resultado como em uma linha de produção. Por outro lado, o professor é o artífice de seu ofício e como tal cabe a ele o processo de fazer aflorar o melhor rendimento possível para cada um de seus discentes, sendo estes o centro de seus processos construtivos de aprendizagem. Por mais que a educação tenha passado por diversos processos de evolução, e tenha sido difícil repensar conceitos e reformular didáticas, os educadores necessitam compreender e se adaptar a cada época e com isso obrigar-se a evoluir como profissionais. "Somos ${ }^{3}$ lo que hacemos, y sobre todo lo que hacemos para cambiar lo que somos." (Galeno, 1981, p.17). Os docentes não são apenas conceitos eternizados em livros ou o exercício da sua prática, os educadores são artesãos em transformar seu ofício em futuro.

Muito tem se discutido sobre educação, em como exercê-la, nos conteúdos a desenvolver, quais métodos terão mais efetividade na aprendizagem, pois percebe-se um desgaste e muitas vezes uma descrença no que tange o papel da instituição educacional, talvez ocasionado pela falta de compreensão entre papel da escola e sua contribuição na socialização e formação, e qual o papel da família e suas responsabilidades familiares, logo se faz necessário tato e sensibilidade, o educador é fundamental na condução do processo e deve zelar pelo desenvolvimento e a construção dos saberes de seus educandos, colocando o aluno como protagonista de sua aprendizagem, obviamente que as formas, ferramentas e tecnologias que contextualizam esta interlocução são importantes e contribuem com a riqueza das vivências, em sintonia com o tradicional que tem sua importância nas práticas, citando Paulo Freire: "Afinal, o espaço pedagógico é um texto para ser constantemente "lido", "interpretado", "escrito" e "reescrito"”. (Freire, 2004, p.95). A visita periódica ao oficio proporciona que um mesmo conceito seja analisado de diversas formas e maturado ao logo da existência.

"A educação é um objecto de um amplo debate social, graças ao qual se constroem crenças e aspirações que formulam diferentes exigências em relação ao comportamento dos professores" (Nóvoa, 1995, p.66). Ao iniciarmos uma provocação que se proponha a refletir a formação dos educadores necessitamos manter os horizontes abertos, pois ao limitarmos o pensamento corremos o risco de restringir as possibilidades de diálogo, referindo-se aos saberes destes seres humanos que se dispõem a serem contribuintes dos processos construtivos de saberes de outros seres humanos. O labor docente não acontece somente em bancos escolares, passeiam com escolhas, tradições de povos, opções de vida, a cada momento ou escolha por mínima que seja terá influência na composição desse educador contribuindo para que este reproduza ou conceitue que é algo que não pode ser repetido em série. "A intervenção pedagógica do professor é influenciada pelo modo como pensa e age nas diversas facetas da sua vida" (Nóvoa, 1995, p.65). As vivências pessoais deixam marcas indeléveis no processo de construção deste indivíduo e também na forma como ele mobiliza os seus saberes de educadores, afinal a historicidade deste educador está ligada diretamente a sua forma de educar e exercer sua profissionalidade.

Ainda que este docente seja único, complexo em significados e experiências é de fundamental importância um conhecimento prévio do seu ofício, a formação inicial é resultado de muita luta e sua implementação foi uma vitória a ciência da educação, porém estes educadores precisam estar cientes que a formação inicial, como o próprio nome já diz, é o início da jornada docente que se faz no exercício diário da profissão e também no diálogo e convivência com os pares e as formações continuadas. "Daí a importância de fortalecer e avançar, cada vez mais, de forma corajosa e autêntica, nos processos formativos já existentes, como na experiência aqui problematizada e refletida". (Tondin, 2019, p.17). O saber docente se produz na convivência social e na sapiência individual para explorar e compor no exercício diário uma possibilidade de aprendizado colaborativo.

A docência não legitima ninguém a trazer consigo todas as verdades e o conhecimento de mundo, pois deriva do exercício de estudos, vivências e reflexões que possibilita ao ser humano construir conhecimento através da interação e refletir sobre conceitos dos que antecederam previamente as mesmas questões. O saber como um todo e principalmente no espaço

\footnotetext{
${ }^{3}$ Somos o que fazemos, mas principalmente o que fazemos para mudar o que somos.
} 
educacional pode ser descrito "como um saber plural, formado pelo amálgama, mais ou menos coerente" (Tardif, 2012, p.36), cientes de que enquanto humanos racionais e históricos necessitamos sempre refletir e ponderar cada uma das vertentes de conceitos.

\subsection{Práticas Pedagógicas Através da Ludicidade}

Toda proposta pedagógica que se inicia com a ludicidade se desenvolve ancorada muito mais na imaginação e suas possibilidades do que na razão ou na repetição mecânica de uma ação. É um trabalho do artesão que se dedica a buscar o melhor desenvolvimento possível de uma obra ou de uma turma de alunos. Ensinar fazendo é uma proposta pedagógica fundamental para incentivar qualquer habilidade. Esta proposta possibilita uma integração gradativa que incentiva e desenvolve gradualmente a experimentação para dessa forma refletir os conceitos e se apropriar deles com a finalidade de explorá-lo, dinamizá-lo e desenvolvê-lo com a proposta de melhorá-lo se apropriando assim do sentido contido neles.

As atividades lúdicas são muito mais que momentos divertidos ou simples passatempos e, sim, momentos de descoberta, construção e compreensão de si; estímulos à autonomia, à criatividade, à expressão pessoal. Dessa forma, possibilitam a aquisição e o desenvolvimento de aspectos importantes para a construção da aprendizagem. Possibilitam, ainda, que educadores e educando se descubram, se integrem e encontrem novas formas de viver a educação (Pereira, 2005, p. 20).

Em seu ofício cabe ao professor à tarefa de encantar seu aluno de tal forma que ele compreenda o processo de ensino como algo mágico que se descortina na frente de seus olhos, para isso o educador precisa transformar o exercício diário de aprender o mundo e compreendê-lo em algo instigante "a transfiguração da banalidade em extraordinário, a metamorfose do trivial em maravilhoso, a conversão inesperada, o salto". (Silva, 2017 p.21), pois é dentro destas possibilidades de compreender o mundo que a educação acontece de forma mediatizada e mágica. Para que o educador consiga proporcionar esta experiência de compreensão de mundo aos seus alunos ele precisa entender o que os move, e uma maneira de se mover e se fazer entender em comunhão com os olhos curiosos de quem vivência esta experiência pela primeira vez. "Poderíamos dizer que quem sabe ensinar é quem já experimentou muitas e diferentes formas de fazer conhecer ou de oferecer ao mundo" (Alliaud, 2015, p.335).

Ao trilhar este caminho descortinamos as multifunções benéficas que a incorporação do lúdico proporciona nas atividades educacionais, pois as tarefas propostas se apropriam da ludicidade com fins educativo onde é possível aprender de forma prazerosa, divertida proporcionando benefícios no que se refere ao desenvolvimento afetivo, físico, cognitivo, social, com utilização em diversas competências, atividades sensório-motoras. Para ter atenção dos discentes o docente precisa saber se expressar em uma linguagem que faça sentido e atraia a atenção de seus alunos, interagir é uma via de mão dupla e para que o diálogo se estabeleça ambos precisam se fazer entender na dinâmica da aprendizagem. Estar disposto à ciência da educação é estar ciente da necessidade de mobilizar todos os conceitos prévios adquiridos e abertos a troca, não bastando apenas o conhecimento prévio, é preciso ter uma alma que ambiciona e se permite compartilhar, sabendo que ser é um [...] "conjunto de comportamentos, conhecimentos, destrezas, atitudes e valores que constituem a especificidade de ser professor" (Nóvoa, 1995, p.64). Construir um processo de construção de saber e torná-lo reflexivo é um dos desafios do educador, sendo o lúdico uma ferramenta que pode auxiliar na construção deste caminho, bem como a tecnologia, são ferramentas que servem para auxiliar o educador, porém jamais substituí-lo.

\subsection{Refletindo as Ambiências em que o Docente se Constrói}

O desafio do docente ultrapassa em muito os conceitos engessados, o péssimo salário ou as condições de ensino que em muitos casos são precárias. O desafio do docente abarca consigo uma pré-disposição a refletir o mundo e a si mesmo, ele 
busca olhar para dentro de si para um exame periódico sobre o seu ofício e o caminho que este está trilhando. "Quando falamos em ambiência, pensamos em humanização por meio do equilíbrio de elementos que compõem os espaços, considerando fatores que permitam o protagonismo e a participação." (Elali, 2009, p.3). Ambiência não se trata apenas de um lugar que possua iluminação, condições de aprendizado, e lugares para os alunos sentarem, quando falamos em ambiências se trata de proporcionar um ambiente para motivar educadores e alunos a aprenderem propiciando segurança, interação e reflexão, se trata de usufruir de conquistas que foram adquiridas há muito tempo, todavia ainda não são exercidas de fato. "Há a preocupação em ressignificar o contexto vivenciado pelas crianças e adolescentes, em uma perspectiva de formação humana integral, de garantia de direitos humanos". (Popenga, 2021 p. 304).

Faz-se necessário a compreensão de que sem a educação desabam-se os pilares ao qual a nossa sociedade está constituída, pelo menos no formato democrático que conhecemos. É preciso fazer um trabalho de resgate histórico sobre a contribuição da educação e dos educadores a forma de vida que conhecemos, pois a sociedade está assentada e fundamentada na educação, entendemos que esta sofre de mazelas e carências, todavia defendemos o diálogo para solucionar esses problemas, pois a opção que temos sem educação é uma opção sombria. (Alliaud, 2015) demonstra exatamente essa realidade em seus estudos ao se referir ao trabalho que o docente carrega quando esta diz: "Temos um trabalho nas mãos que nos conecta com a possibilidade de formação/transformação de pessoas, com a transmissão da cultura às novas gerações". (p. 344).

Por mais desesperançosos que os seres humanos estejam a respeito da educação, é tácito que sem ela não se tem cultura nem sociedade, ainda que algo tenha se perdido e exista uma descrença social a respeito de sua relevância para o mundo em si, sabemos que não é possível pensar em sociedade organizada que não alicerçada na educação como um bem público que precisa estar ao alcance de todos. "Se a educação sozinha, não transforma a sociedade, sem ela tampouco a sociedade muda." (Freire, 2000, p.67). A educação se tornou um bem imputado aos educadores cabendo a estes a responsabilidade de educar, sendo que por vezes o que se espera é de forma de aprendizagem industrializada, por olvidarem como é que a educação realmente acontece, o tempo necessário para introjetar vivências auxiliarão na construção do ser sujeito, do quanto à forma dialógica é eficaz e gratificante oportunizando a este educando ser o centro de seu processo e ao educador as observâncias de suas contribuições, sendo agente possibilitador "Não apenas se aprende o que faz, fez ou viveu, mas nesses processos o que os outros fazem ou fizeram é altamente formativo. Novamente o potencial instrutivo dessas experiências depende das condições em que são desenvolvidas". (Alliaud, 2015, p. 341).

É preciso entender a contribuição da educação dentro de todo o convívio social e também compreender essa vocação ontológica que o ser humano tem de ser mais do que mero repetidor de conteúdo "[...] jamais foi fraca em mim a certeza de que vale a pena lutar contra os descaminhos que nos obstaculizam de Ser Mais". (Freire, 2004, p.142). Em tempo, sem ser ponto final nos provocamos a reflexão de como nos construímos educadores, em que motivou nossas jornadas, por suposto nos construímos com algumas certezas, acreditamos, vivenciamos, para em algum momento revisitarmos essas certezas e as desconstruirmos.

As mudanças podem parecer lentas, ou mais visíveis aos olhos, mas a reconstrução inicia-se novamente, pois ser educador é participar ativamente desse processo, é vivenciá-lo sendo que ela não se faz em planos cartesianos e sim de forma circular e ininterrupta, o que podemos utilizar são os nossos lugares de fala e os nossos motivadores para que continuemos a dialogar e refletir nossa jornada, "É, antes com o que somos e com o que fazemos porque escolhemos fazê-lo: a passagem do patrimônio cultural às novas gerações. Mais do que amor pelas crianças, é paixão pela transmissão e pelo que está sendo transmitido". (Alliaud, 2015, p. 344), precisamos primar pelo mundo que queremos construir para os que vierem depois. 


\section{Considerações Finais}

Ensinar é uma tarefa desafiadora, indiferente da história de vida individual, ou como se se realizou a formação inicial, o aporte teórico que este docente possua, ensinar não é tarefa fácil, apesar de a experiência auxiliar um pouco, pois permite que o docente seja experimentado no decorrer da sua jornada, nem por isso cada nova turma de alunos deixa de ser um desafio. Este educador é desafiado diariamente a fazer o seu melhor com as condições que possui, seja na carência de recursos resultado de uma desigualdade social estrutural seja em países de primeiro mundo com recursos ilimitados, educar ainda é uma tarefa que requisita o lado humano de cada indivíduo.

Educar é ter o pensamento voltado ao bem comum e na construção do coletivo, é saber que temperança e parcimônia não devem ser confundidas com passividade e acomodação, o educador é por natureza um ser humano combativo e sabe que as mudanças não se dão no vazio. O profissional da educação é motivado por uma fé na vida e na sociedade a tal ponto que passa a vida auxiliando na construção de pensamentos e ideias. Ao contrário do que muitos dizem a educação não é doutrinadora; o bom educador possibilita o pensamento livre de seus alunos e constrói formas para que seus educandos possam refletir com base em pensamentos e conhecimentos estudados previamente.

Os problemas da nossa sociedade são cíclicos e se repetem ao longo dos anos, não é de hoje que existe a fome, as carências e dificuldades de acessos do que deveria ser um bem comum garantido a todos, e aos que assim não tivessem acesso o Estado tem por obrigação garantir. Ainda assim o educador sabe que não basta esperar o estado ou a boa vontade, é necessário formar cidadãos que reflitam e requisitem seus direitos básicos. É dentro da educação que é possível erradicar a violência, a disparidade, a fome, o medo. A educação ilumina, salva, aflora, possibilita. O papel do educador é um dos principais dentro do cenário social, pois o médico, o engenheiro, o gari e a doceira todos foram à escola ou deveriam ter tido o direito de ir. Cabe à sociedade reconhecer o papel fundamental do educador para que assim ele possa exercer o seu papel de forma democrática com acessibilidade e equidade.

Precisamos dialogar sobre a formação inicial e continuada dos docentes; precisamos garantir escolas e qualidade na educação para compor uma sociedade mais justa. Não se pode acreditar na falácia que o Estado irá garantir de forma voluntária uma educação de qualidade se o povo não o reivindicar. A profissionalidade docente é constituída de vivências, olhares e compartilhamento, enquanto seres culturais é necessário pensar a educação com olhar histórico para que a partir deste construir uma perspectiva de futuro ancorado nos ensinamentos precursores para que nossas contribuições tenham um ponto de partida neste construção. Entendemos que as pesquisas na linha de formação docente, saberes e ambiências não findarão pois o ser humano traz consigo angustias e uma necessidade constante de evoluir enquanto gente, assim como dizia (Freire, 1987), ser gente é ter ciência de ser incompleto e viver em constante busca de ser melhor.

\section{Referências}

Alliaud, A. (2015). Los Artesanos de la Enseñanza Pos-Moderna. Hacia El Esbozo De Una Propuesta, v. 1(2014), $319-349$.

Arroyo, M. G. (2000). Oficio de Mestre. Imagens e auto-imagens. 3.ed.Petrópolis/RJ: Editora Vozes.

Braga, N.P.S. \& Rodrigues, A. (2020). Ser e estar professor na educação infantil: significações em movimento. Revista Research, Society and Development. 9. 4. e32942735. ISSN 2525-3409. 951-970

Elali, G. A. (2009). Relações entre comportamento humano e ambiência: uma reflexão com base na psicologia ambiental., Anais do Colóquio Ambiências Compartilhadas., 1-17.

Freire, P. (1979). Conscientização. Teoria e Prática da Libertação. Uma introdução ao pensamento de Paulo Freire. São Paulo. Cortez \& Moraes.

Freire, P. (2004). Pedagogia da autonomia: saberes necessários a prática educativa. São Paulo: Paz e Terra.

Freire, P. (1987). Pedagogia do Oprimido. $17^{\text {a }}$ ed. Rio de Janeiro, Paz e Terra.

Freire, P. (2000). Pedagogia da indignação: cartas pedagógicas e outros escritos. Apresentação de Ana Maria Araújo Freire. Carta-prefácio de Balduino A. Andreola. São Paulo: Editora UNESP. 
Research, Society and Development, v. 10, n. 10, e345101018979, 2021

(CC BY 4.0) | ISSN 2525-3409 | DOI: http://dx.doi.org/10.33448/rsd-v10i10.18979

Galeano, E. H. (1982) Voces de nuestro tiempo. Editorial Universidade Centro americana. Educa, ISBN 8883602377, 9788483602379.

Nóvoa, A. (1995). Formação de professores e profissão docente. In. Os professores e a sua formação. Nóvoa, A.(org.) 2. ed. Portugal: Publicações Dom Quixote.

Ghedin, E.\& Franco, M. A. S. (2011). Questões de método na construção da pesquisa em educação. 2.ed. São Paulo: Cortez.

Kauark, Fabiana. Metodologia da pesquisa: guia prático/Fabiana Kauark, Fenanda Castro Manhães e Carlos Henrique Medeiros. Itabuna: Via Litterarum, 2010

Minayo C.S \& Deslandes, S.F. \& Gomes, R. (2002). Pesquisa social: teoria, método e criatividade. Petrópolis: Vozes.

Pereira, L. H. P. (2005). Bioexpressão: a caminho de uma educação lúdica para a formação de educadores. Rio de Janeiro: Mauad X: Bapera.

Pimenta, S. G. (2012). Formação de professores: identidade e saberes da docência. In: Pimenta, S. G. Saberes Pedagógicos e atividade docente. São Paulo: Cortez. 15-38.

Pires, C. S. \& Veiga, A.M. R. (2020). Costurando possibilidades na complexidade da docência: a bricolagem na trajetória auto(trans)formativa. Revista Research, Society and Development. 9. 4. e32942735. ISSN 2525-3409. 971-982.

Popenga, M. (2021). et al, Da Paz no Currículo Escolar. 301-315.

Saviani, D. (2013). História das Ideias pedagógicas no Brasil. Campinas: Autores Associados.

Silva, Juremir Machado da. Diferença e descobrimento. O que é o imaginário? A hipótese do excedente de significação. Porto Alegre: Sulina, 2017.

Tardif, M. (2012). Saberes Docentes e Formação Profissional. Petrópolis, Rio de Janeiro. $5^{\text {a }}$ edição.

Tondin, C. F. \& Kroth G. \& Junges. S. A. \& Teresinha. C. (2019). O Conhecimento Do Conhecimento: Uma Estratégia Da Escola Para Ensinar a Viver, Revista Contexto \& Educação. 34. 107. 5-18. 